\title{
Alimentação, sistema agroalimentar e os consumidores: novas conexões para o desenvolvimento rural ${ }^{*}$
}

\author{
Rozane Marcia Triches** \\ Sergio Schneider*** \\ Recibido: 20I4-02-20 Aprobado: 2014-II-04 Disponible en línea: 2015-15-03 \\ doi:I0.III44/Javeriana.cdrı2-75.asac
}

Cómo citar este artículo: Triches, R., \& Schneider, S. (2015). Alimentação, sistema agroalimentar e os consumidores: novas conexões para o desenvolvimento rural. Cuadernos de Desarrollo Rural, I2(75), 55-75. http://dx.doi. org/10.III44/Javeriana.cdrı2-75.asac

\footnotetext{
* Produto da tese da autora intitulada Reconectando a produção ao consumo: a aquisição de gêneros alimentícios da agricultura familiar para o Programa de Alimentação Escolar, defendida em 2010.

** Professora Coordenadora do Curso de NutriçãoCoordenadora da Pós-Graduação Lato Sensu em Segurança Alimentar e NutricionalUniversidade Federal da Fronteira Sul. Campus Realeza.

Email: rozane.triches@gmail.com

*** Professor de Sociologia do Desenvolvimento Rural Universidade Federal do Rio Grande do Sul. Pós-Graduação em Sociologia e PG Desenvolvimento Rural. Email: schneide@ufrgs.br
} 


\section{Resumo}

Propomos abordar o movimento de conexão e desconexão da cadeia de abastecimento dada pelas relações intermediadas pelo alimento. Evidenciamos que há uma hegemonia do sistema agroalimentar global que distanciou quem produz e quem consome com conseqüências para ambos, gerando movimentos de crítica e contestação que propõem novas relações de reaproximação entre estas esferas. De outro lado, há uma lacuna entre produção e consumo do ponto de vista teórico/analítico e a sociologia da alimentação pode ser considerada como potencial campo de ligação para entender estas dinâmicas. Há necessidade de salientar a alimentação, os sistemas agroalimentares e consumo nos estudos do desenvolvimento rural.

\section{Palavras-chave:}

sociologia da alimentação; desenvolvimento rural; consumo alimentar; produção de alimentos; cadeias de abastecimento alimentar; Brasil

\section{Alimentación, sistema agroalimentario y consumidores: nuevas conexiones para el desarrollo rural}

\section{Resumen}

El análisis de los movimientos de conexión y desconexión de la cadena de abastecimiento dada por las relaciones intermediadas entre los productos alimenticios demuestra que existe una hegemonía del sistema agroalimentario global que distanció a quien produce de quien consume. Este paradigma genera consecuencias para ambos, creando movimientos de crítica y contestación que proponen nuevas relaciones de aproximación entre estas esferas. Por otra parte, existe una brecha entre producción y consumo desde el punto de vista teórico/analítico, y la sociología de la alimentación puede ser considerada como potencial campo de enlace para entender estas dinámicas. Hay una necesidad de exaltar la importancia de la alimentación, los sistemas agroalimentarios y el consumo en los estudios de desarrollo rural.

\section{Palabras clave:}

sociología de la alimentación; desarrollo rural; consumo alimenticio; producción de alimentos; cadenas de abastecimiento alimentario; Brasil 


\title{
Feeding, Agrifood System, and Consumers: New Connections for Rural Development
}

\begin{abstract}
We propose to address the connection and disconnection movement of the supply chain, given by the relationships mediated by food products. We want to demonstrate that the existence of hegemony in the global agrifood system created a distance between those who produce and those who consume, with consequences for both sides; thus generating critic and response movements that propose new approach relationships between these spheres. On the other hand, there is a chasm between production and consumption from a theoretical/analytical point of view, and the sociology of feeding may be considered as a potential linking field to understand these dynamics. There is the need to highlight feeding, agrifood systems, and consumption in rural development studies.
\end{abstract}

Keywords:

sociology of feeding; rural development; food consumption; food production; food supply chains; Brazil

\section{Alimentation, système agroalimentaire et consommateurs: nouvelles connexions pour le développement rural}

\section{Résumé}

L'analyse des mouvements de connexion et déconnexion de la chaîne d’approvisionnement donnée pour les rapports intermédiaires entre les produits alimentaires montre qu'il y a une hégémonie du système agroalimentaire global qu'éloigne aux producteurs de consommateurs. Ce paradigme crée des conséquences pour les deux, en créant des mouvements de critique et contestation pour faire des nouveaux rapports de rapprochement entre ces deux sphères. Par ailleurs, il y a un écart entre la production et la consommation depuis le point de vue théorique/analytique, et la sociologie de l'alimentation peut être considéré en tant qu'un potentiel champ de branchement pour comprendre ces dynamiques. On a le besoin d'exalter l'importance de l'alimentation, les systèmes agroalimentaires et la consommation dans les études de développement rural.

Mots-clés:

sociologie de l'alimentation; développement rural; consommation alimentaire; production d'aliments; chaînes d’approvisionnement alimentaire; Brésil 


\section{Introdução}

A sociedade contemporânea caracteriza-se por situações que podem parecer antípodas e antagônicas à primeira vista. Como é possível a fome e a pobreza em um contexto de crescentes excedentes e recordes de produtividade de alimentos, fibras e matérias-prima? Como aceitar que os humanos sejam capazes de feitos memoráveis no campo das tecnologias espaciais e informacionais, apenas para citar os campos promissores, e continua a devastação dos recursos naturais mais nobres e fundamentais à vida como a água, o solo e a biodiversidade?

Em um mundo de contradições e contrasensos o descolamento entre a produção e o consumo de alimentos soma-se às contradições mais evidentes. Por um lado, as décadas finais do século XX assistiram à formação de um sistema agroalimentar que logrou sua internacionalização e hoje influencia a produção, a distribuição e o consumo de alimentos, chegando ao estágio de ditar dietas alimentares para amplos estratos da população urbana. Por outro lado, percebe-se consumidores cada vez mais confusos e incertos com suas dietas alimentares e o que Bauman (2007) chamou de conveniência e a moda do consumerismo, pelo qual a identidade dos indivíduos já não se dá mais por sua posição na divisão social do trabalho, mas pelo padrão de consumo.

Não há como negar que com o advento do capitalismo e da transformação dos alimentos em mercadorias, o ato corriqueiro e vital de alimentar-se se converteu em uma questão política e econômica nem sempre ética e equitativa, colaborando para reações e mudanças nas relações entre produção e consumo que devem ser melhor compreendidas (Lang, Barling e Caraher, 2009). Neste sentido, os problemas alimentares tornam-se fatos sociais relevantes para a sociologia e reclamam por perspectivas teórico-metodológicas que requerem maior abrangência e compreensão.

Pretendemos neste artigo debruçar-nos sobre duas grandes desconexões a serem compreendidas e analisadas. Em primeiro lugar, a desconexão teórica entre consumo e produção e a necessidade de articular em um mesmo marco analítico, duas searas que até então são estudadas separadamente sob domínios epistemológicos distintos. Com isso chamamos a atenção sobre a centralidade da alimentação como fato social e sua importância no campo de estudos da sociologia. Em segundo lugar, evidenciar esta complexidade empiricamente, analisando o movimento de desconexão da cadeia de abastecimento e sua relação com o desenvolvimento. Considera-se que as mudanças entre produção e consumo moldam e são moldadas por diferentes modelos de desenvolvimento dentro do sistema capitalista que podem priorizar tanto a acumulação econômica, quanto o bem estar social. Dessa forma, importa 
evidenciar que há uma hegemonia do sistema agroalimentar global que levou ao distanciamento entre quem produz e quem consome com drásticas conseqüências para ambos. Isto gerou movimentos de crítica e contestação, que propõem novas relações de reaproximação entre estas esferas, dinamizando cadeias curtas de abastecimento alimentar.

Considerando estas duas questões de análise, as experiências e práticas contestadoras do atual sistema agroalimentar não podem ser compreendidas apenas pelo ponto de vista da produção e, portanto do olhar restrito ao rural e a fatores econômicos. Estes novos movimentos indicam que as mudanças não se efetivam se restritas à desestruturação da produção, mas devem ser acompanhadas por uma revisão por parte do consumo. Portanto, como componente intrínseco, o consumidor deve movimentar essa engrenagem, realimentando o processo em prol da institucionalização de um novo modelo agroalimentar. Assim, trata-se do consumo estar envolvido em novas dinâmicas e políticas, que remetem a valorações do local, da qualidade dos alimentos e da relação do meio urbano com o meio rural.

Estamos convencidos que para entender estas mudanças é necessário que se concilie os estudos do consumo e da produção, considerando que ambos fazem parte de um processo dinâmico de transformações. Defendemos o argumento que a cultura de produção e a cultura de consumo não são "purificadas", não são categorias separadas da vida social, mas uma constitui a outra (Goodman e Dupuis, 2002) e que maior atenção deve ser dada ao processo de mudança nestas relações (Douglas e Isherwood, 2004). Portanto, considerando que o tratamento entre estes domínios em estudos agroalimentares ainda é muito assimétrico, a conjunção entre os campos da sociologia rural e da sociologia da alimentação se torna central para estabelecer novas epistemologias.

Neste sentido, o presente artigo se propõe dissertar sobre a pertinência cada vez maior do tema da alimentação nas discussões do desenvolvimento e, mais diretamente, no que tange ao desenvolvimento rural, ultrapassando o campo restrito das ciências da saúde a que estava confinado. Outrossim, o enfoque agroalimentar como linha de preocupações para os estudiosos do desenvolvimento rural se torna relevante, porque implica em compreender como os agricultores familiares se incorporam nesse novo regime de consumo e produção flexíveis (Schneider, 2010) e se isso os torna mais autônomos, favorecendo formas mais equânimes e sustentáveis de desenvolvimento.

O artigo está estruturado a partir da introdução em três partes. Na primeira pretendemos fazer uma rápida introdução à sociologia da alimentação como campo 
epistemológico emergente, que objetiva aproximar teorias relativas ao consumo e à produção de alimentos. Em um segundo momento discorrer sobre a desconexão da produção e do consumo de alimentos no sistema agroalimentar atual. A seguir, enfatizar os processos que se ligam a novos elementos relativos ao encurtamento da cadeia alimentar e que vão se delineando e sendo abordados por um novo paradigma de desenvolvimento rural em que os atores sociais, principalmente no campo do consumo, têm sido fundamentais.

\section{A sociologia da alimentação como campo epistemológico emergente}

A atenção da sociologia ao tema da alimentação é recente, talvez porque até pouco tempo não era considerado um problema social, apenas uma necessidade biológica dentro de uma esfera privada e como algo dado, inerente ao comportamento cotidiano (Díaz Méndez e Gómez Benito, 2004). Outra hipótese que pode ser referida a este autismo da sociologia da alimentação seria a predominância das análises culturalistas (antropológicas) como teorias explicativas para o consumo e das análises marxistas para explicar as questões relativas à produção.

Esta dicotomia explicativa compunha um modelo de desagregação e distanciamento entre os campos da produção e consumo, refletindo uma real distância empírica entre eles, incentivada pelo modelo de desenvolvimento pautado na modernização agrícola.

Este distanciamento da cadeia de abastecimento alimentar provocou diversos problemas que evocam áreas que vão alem do próprio campo disciplinar para confrontá-los e entendê-los. Pelo lado da área da saúde e do consumo, a sociologia da alimentação passa a ser referenciada como forma de perceber que os problemas nutricionais atuais tenderiam a estar associados mais ao excesso alimentar e má qualidade nutricional das dietas do que com a sua escassez (Mennel, Murcott e Otterloo, I992). A constatação das transições epidemiológica e nutricional fomentou ainda mais a associação entre os problemas alimentares e de saúde às condições de vida da sociedade moderna industrializada, culminando com o reconhecimento da necessidade de envolver a sociologia nos estudos sobre alimentação. Dessa forma, a emergência ou re-emergência (Ward, Coveney e Henderson, 20ıo) da sociologia da alimentação tem sido motivada pelas questões de saúde e de consumo, e neste último inserem-se as questões políticas, ambientais, morais que dão conta de um 
emaranhado de construtos de qualidade dos alimentos, da própria construção da identidade do consumidor, entre outros.

Ligando-se à outra ponta, a sociologia da alimentação não tem como ignorar as múltiplas facetas e relações deste tema com o modelo de produção agroalimentar estabelecido e com os mercados. Neste debate estariam a globalização do abastecimento e o aumento dos riscos oferecidos pelo uso de biotecnologias, nanotecnologias, pesticidas, aditivos químicos e escândalos alimentares, noticiados frequentemente pela mídia. Também pode-se fazer referência à globalização no que tange às questões econômicas e à influência nos preços dos alimentos, afetando a segurança alimentar das populações. $\mathrm{O}$ aumento dos preços dado pelo acréscimo da demanda e diminuição da oferta, aumento dos custos de produção e o uso de produtos vegetais para produção de biodisel, levaria à dificuldade de acesso das populações mais carentes aos alimentos.

Também não há como negar as conseqüências do modelo agroalimentar dominante no que tange ao próprio meio rural. A concentração de terras, de capital e a exploração, exclusão e emigração de pequenos agricultores é factual e bem demonstrado nas últimas décadas. Assim como a concentração da riqueza produzida pela industrialização dos alimentos por grandes indústrias à montante e à jusante da produção e pelas crescentes fusões entre empresas (Perez-Cassarino, 20I2).

Estas questões de natureza socioeconômica alinham-se às implicações ecológicas da cadeia de abastecimento, favorecendo uma abordagem socioecológica da alimentação. Preocupações éticas relativas à produção, ao consumo e ao transporte de alimentos permeiam as discussões sobre a localização, a promoção de justiça social, culminando na construção de um modelo de desenvolvimento mais sustentável.

$\mathrm{Na}$ esteira destas preocupações, o consumo de alimentos baratos e com alta densidade calórica, promovido pela indústria alimentícia e pela mídia tem sido relacionado ao aumento substancial do sobrepeso e da obesidade, com altos custos ambientais. Por um lado, produzir alimentos baratos significa muitas vezes usar os recursos naturais de forma predatória com a contaminação e poluição do solo, da água e do ar, diminuição da biodiversidade e não pagamento dos serviços ecossistêmicos. Por outro lado, também significa consumir gêneros que produzem mais lixo, utilizam mais tecnologia e ingredientes tóxicos e viajam longas distâncias emitindo maior quantidade de gases poluentes.

Portanto, corroborando com os autores que têm se dedicado à sociologia da alimentação (Poulain, 2004; Mennell, Murcott e Otterloo, 1992; Goodman e DuPuis, 2002; Díaz Méndez e Gómez Benito, 2004), um de seus objetivos atuais é o de 
colocar em evidência um importante fato social, que tem sido marginal enquanto tema da sociologia. Além disso, articular e aproximar estudos relativos à produção e consumo de alimentos nos mesmos marcos teóricos. Este esforço vem no sentido de melhor compreender este que é ao mesmo tempo cotidiano, mas também complexo ato de se alimentar, como determinante e determinado pela sociedade e como central nos rumos que se pretende para o desenvolvimento.

Acreditamos que somente a partir de uma compreensão mais abrangente do papel da alimentação é que poderemos entender o desenvolvimento rural a partir dos sistemas agroalimentares e de suas novas configurações. Para isso, passamos a considerar na análise da relação entre produção e consumo, a leitura histórica e estrutural do sistema dominante como possíveis feitos da ação dos atores, dentre os quais, os consumidores.

\section{O sistema agroalimentar e o distanciamento da cadeia de abastecimento}

Desde os primórdios da década de 1990 emergiu uma literatura na sociologia da agricultura preocupada em compreender as transformações dos regimes alimentares no período do capitalismo fordista (Friedmann e McMichael, 1989; McMichael, 2009; Friedmann, 1993b). As análises dos teóricos da regulação ressaltavam as relações sistêmicas entre as dietas alimentares e os fenômenos econômicos, sociais e políticos em nível global, que influenciavam as relações entre os Estados Nacionais e o sistema agroalimentar em escala mundial.

Um dos principais expoentes desta teoria, Harriet Friedmann (1993b), pontua que a partir dos quatro últimos séculos, e mais intensamente nos últimos ıoo anos, a alimentação e a agricultura passaram a ser organizadas em escala mundial. A especialização da produção agrícola estendida entre continentes abriu um vasto espaço onde as pessoas vivem e a origem dos produtos que consomem, entre o trabalho que realizam e os objetos que utilizam. Segundo a autora, a relação entre as pessoas, e, entre as pessoas e o seu território tornam-se organizadas em uma escala para além da observação direta, o que para ela foi um divisor de águas na história humana.

Utilizando a alegoria do "Rei Midas", Friedmann (1993a) aponta dois princípios da agricultura industrializada: a durabilidade e a distância. Para serem bons como o ouro, os alimentos deveriam durar como ouro e viajar tanto quanto ele. O princípio da distância refere-se ao esforço de tornar o local irrelevante. A localização da 
produção pode mudar tão rapidamente quanto as condições de mercado o exigirem. Para que o alimento seja independente do local, é necessário também que o seja do tempo. Alimentos que duram mais tempo podem viajar longas distâncias e esperar pelo melhor tempo, considerando as condições flutuantes do mercado.

A partir do primeiro regime alimentar, constituído no período final da hegemonia britânica (1870-1914), quando os alimentos passaram a ser comprados nos mercados, um segundo regime foi criado, no final da década de 1940, sendo comumente identificado como período "fordista". Nesse período desenvolvem-se as tecnologias patrocinadas pelo Estado, para garantir o crescimento exponencial da produção de alimentos baratos no período pós-guerra, para alimentar a força de trabalho industrial que se concentrava na zona urbana. Essa regulação social deu suporte ao que se tornou o modelo superintensivo de produção agrícola e abastecimento alimentar, desenvolvendo-se globalmente e conduzindo a uma reconfiguração desigual do cenário agrário (Friedmann e McMichael, 1989).

Mundialmente, o uso constante de inovações tecnológicas foi sustentado por uma ideologia modernizante e progressiva. A distribuição passou a ser em grande escala e, nesse processo, a alimentação tornou-se um mercado de consumo de massa (Fischler, 1995; Lang e Heasman, 2004), com produtos altamente transformados por procedimentos industriais de vanguarda, concebidos e comercializados com o apoio das mais modernas técnicas do marketing, packaging e publicidade e distribuídos por redes comerciais que não cessavam de aperfeiçoar seu poder e complexidade, colocando em ação uma logística extremamente elaborada, e ressaltando, dessa forma, a supremacia da comercialização de alimentos e das indústrias de alimentos.

Cada vez mais, passou-se a produzir alimentos com maior durabilidade, com aditivos químicos e com processos rígidos de higiene e sanidade em uma tentativa de adaptar a natureza ao capitalismo. Nessa abordagem, importante frisar as contribuições de Goodman, Sorj e Wilkinson (1990) e sua obra Da Lavoura às Biotecnologias, em que apontam para a apropriação e a substituição da natureza pelo capital. Utilizando-se desses dois artifícios, o processo de produção rural levaria claramente a uma capitalização crescente das atividades agrícolas.

Relativamente ao papel do Estado, o terceiro regime alimentar corresponde ao modelo "liberal produtivista" e ao momento atual da globalização financeira, a partir do final da década de 1980 (Friedmann, 2005). A subordinação dos alimentos ao mercado autorregulado envolve o desligamento das relações econômicas da região e das pessoas. Cada passo da cadeia alimentar e sua complexidade promovem uma forte separação da produção e do consumo de uma comunidade. A necessária 
mediação da produção e do consumo é feita pelo capital, isto é, por empresas em que os lucros dependem da distância e da durabilidade. É nesse ponto que se destaca a abordagem de Ploeg (2008) quando se refere aos impérios alimentares e ao domínio das grandes corporações, bem como, sua financeirização (Clapp e Fuchs, 2009), restringindo a ação do Estado como promotor de redistribuição de riquezas e redutor de desigualdades (Perez-Cassarino, 20I2),

Já em relação a isso, a produção de alimentos abundantes e baratos não seria possível sem a contribuição de países em desenvolvimento. Bonanno (I994) destaca que esse processo de integração gerou desigualdades regionais, como também, em termos de produção, dificultou o crescimento econômico desses países. Mais especificamente, o desenvolvimento de monocultivos para o mercado global, diminuiu a autossuficiência alimentar e aumentou a dívida externa. Em termos de vinculação entre produção e consumo, as cadeias transnacionais de produção criaram um aumento de divergências entre a demanda de alimentos e a produção local.

Nesta reflexão tornam-se chave a compreensão das mudanças demográficas, sociais, econômicas e políticas que foram acompanhadas por uma tendência ascendente de deslocamento entre a produção de alimentos e o seu consumo. Se em uma sociedade tradicional e culturalmente mais fechada esse processo era estritamente localizado, em uma sociedade moderna e contemporânea, já não há delimitação de espaço nem de tempo. Os alimentos tornam-se mercadorias e, como tais, são tratados, buscando a sua durabilidade, sua desterritorialização, apropriando-se do seu caráter “natural” e substituindo-o. A técnica e a ciência a favor da industrialização da natureza e dos modelos econômicos e políticos tornam-se interventoras, mediadoras, e compõem vários elos que distanciam o consumidor daquilo que consome, o produtor daquilo que produz, transformando-os ambos, consumidores e produtores, num sistema abstrato e com mútuo desconhecimento. Esse distanciamento não ocorreu sem prejuízos de ambas as partes e da natureza. Daí decorre um movimento antagônico, mas que também pertenceria e comporia um complexo terceiro regime agroalimentar que é o do "esverdeamento" do capitalismo (Friedmann, 2005).

Parte desta conjuntura do terceiro regime inclui, portanto, uma agricultura globalizada de alimentos e combustíveis em tensão com várias formas de localismos. Como as milhas alimentares aumentam os custos e a produção em massa padroniza os processos, os movimentos como o Slow Food e Fair Trade, e os pequenos produtores de produtos orgânicos expandem suas bases sociais baseados na democracia, ecologia e qualidade (McMichael, 2009). Dessa forma, torna-se central na análise de 
mudanças estruturais entender como os atores se tornam agentes de mudança e qual passa a ser seu papel na reordenação das cadeias de abastecimento, fomentando este contra-movimento.

\section{O lugar do consumidor no movimento de aproximação entre produção e consumo de alimentos}

As implicações do panorama agroalimentar contemporâneo podem ser sumarizadas como um conjunto de fatores referentes às problemáticas do consumo massificado, da verticalização da cadeia alimentar e do produtivismo agrícola (Ilbery, Morris, Buller, Maye, Kneafsey, 2005). Em contraposição, tem ocorrido não somente na Europa, mas também nos países latino-americanos, aumento no número de tendências sociais contrárias e contestadoras de diversas origens. Coletivamente, estes movimentos passaram a oferecer grandes desafios para os dogmas, promovendo a base de novas agendas de políticas rurais territorializadas e sustentáveis, sucedendo o paradigma produtivista (Morgan, Marsden e Murdoch, 2006).

Nesse contexto, o processo de reaproximação da produção ao consumo, implicando o reconhecimento da ruptura e da desconexão na cadeia alimentar, apoia a ideia da sobrevivência agrícola e da restauração da confiança na produção de alimentos pelo consumidor, mediante cadeias alimentares localizadas e pautadas em novas concepções e construções de qualidade, “quality turn” (Goodman, 2003). Para Slee e Kirwan (2009), juntos, quality e consumption turns incluem a crescente importância da localização da produção como forma de valorizar localmente ativos específicos; a necessidade de reconhecer a "natureza" nos processos de produção de alimentos, ao invés de simplesmente vê-la como um ônus a ser superado; as preocupações dos consumidores sobre determinados aspectos da cadeia de abastecimento alimentar, juntamente com construções de valor cada vez mais complexas; e o reconhecimento da contribuição da agricultura e seu aspecto multifuncional para o desenvolvimento rural.

Mediante essa complexidade, alguns autores (Ploeg, Renting, Brunori, Knickel, Mannion, Marsden, Roest, Sevilla-Guzmán, Ventura, 2000; Marsden. Banks, Bristow, 2000; Marsden, 2003) vêm defendendo a mudança paradigmática da modernização agrícola para o desenvolvimento rural, em que este estaria substituindo teórica, prática e politicamente o anterior. Além dos “turns" do consumo e da qualidade, outra motivação para esse processo estaria nas estratégias, 
nas práticas, nas identidades, nas políticas, nas instituições e nas novas redes incorporadas ao rural. As cadeias de abastecimento alimentar projetam-se como dimensões-chave nos novos padrões emergentes de desenvolvimento rural. Para Marsden et al. (2000), entender a criação, a operação e o desenvolvimento dessas novas cadeias é significativamente importante para abordar esses aspectos referentes ao novo paradigma.

Por sua vez, para poder caracterizar uma cadeia curta como existente, segundo Marsden (2003), ela teria de ter a habilidade de engendrar alguma forma de conexão entre o consumidor e o produtor. Não necessariamente ela estaria relacionada ao tempo e à distância percorrida, mas ao fato de o produto chegar ao consumidor envolto de informação, dando-lhe condições de fazer conexões e associações com um mínimo de dados sobre o lugar e o espaço onde foi produzido, os valores e pessoas envolvidas e os métodos empregados. Opera-se com o princípio de que quanto mais imerso em um sistema de valores e práticas específicas um produto venha a ser, mais escasso ele é no mercado pela distinção de suas qualidades e proveniência.

No caso específico das mudanças agroalimentares, Friedmann (1993a) já frisava que a localização e a sazonalidade dos alimentos constituiriam uma solução promissora e pontuava dois movimentos importantes na desestabilização do sistema alimentar dominante: um baseado no empobrecimento e na marginalidade impostos por turbulentas mudanças nos mercados e nos imperativos de exportação que faziam as pessoas despossuídas agirem com criatividade e energia na busca de suas próprias soluções; outro, baseado em consumidores cidadãos urbanos interessados em promover produções sustentáveis, diversificadas e locais.

Relativo ao primeiro movimento, Ploeg et al. (2000) relacionam a emergência de um novo modelo de desenvolvimento rural com a resposta ao "squeeze" promovido pela modernização da agricultura. Para esses autores, nos anos 1990 , começa-se a sentir muito fortemente os custos dessa modernização no que tange às despesas monetárias associadas com o crescimento da necessidade de recursos externos e com tecnologias novas e mais caras, além dos custos de transação e de energia intrínsecos às regulamentações e investimentos obrigatórios. Esse aumento dos custos da produção inviabilizaria a atividade por não compensar os preços de venda, demandando estratégias criativas e inovadoras para diminuir os gastos e otimizar os ganhos.

Nesse sentido, os agricultores buscariam maior autonomia, a partir da redefinição de relações e interações com os espaços sociais e o ambiente institucional, buscando 
formas diversificadas de reação e inovação (Wiskerke e Ploeg, 2004). Amin e Cohendet (2004) remetem os processos de inovação e desenvolvimento tecnológico à imersão (embeddedness) em contextos sociais, e a invenção e a criatividade como sendo frutos de um intenso processo de interação e troca de experiências a partir de situações práticas e contingentes. Esses processos seriam, em última instância, soluções criativas e inovadoras que os agricultores utilizariam para enfrentar problemas complexos. Exemplo disto seriam as estratégias de venda direta ao consumidor de produtos "diferenciados", resultando na agregação de valor ao produto e diminuição dos custos de produção e transação comparativamente ao seu alinhamento às cadeias longas de abastecimento.

No que diz respeito ao segundo movimento citado por Friedmann (1993a), um novo ator, até então desconsiderado, tem sido o foco dos interesses. Para Goodman (2002; 2004), e Goodman e DuPuis (2002), o consumidor parece estar com o poder na condução das indústrias e varejos de alimentos e, portanto, a sua relação com a produção passa a ser preponderante. A preocupação em relação ao consumo nos estudos agroalimentares toma corpo e passa a reconhecer-se o alimento como muito mais que apenas uma mercadoria como outra qualquer.

Em uma análise entre os autores e suas defesas conceituais sobre o consumo e como se explica a sua variabilidade, para Warde (1997) há quatro tendências principais. A primeira delas se refere à abordagem de Bourdieu (2007), em que o consumo está associado ao gosto e esse seria definido por identificações unitárias de estilos de vida gerados na competição entre classes sociais, ou seja, o grupo social determinaria normas de consumo, e o indivíduo aprenderia gostos apropriados e comportamentos de consumo de acordo com os parâmetros de sua cultura. Conclui-se, por Bourdieu, que o gosto é enraizado socialmente e suas normas são altamente reguladas pela classe a que pertence. Nesse contexto, não haveria um mínimo espaço para a escolha do indivíduo.

A segunda seria a coletivização, interpretada como a massificação sem regramentos. O gosto seria homogeneizado por uma cultura popular dominante e essa tendência seria caracterizada pela informalização, por um déficit de regulação, desvinculada das tradições ou culturas específicas para a estandartização dos gostos e midiatização das mensagens, caracterizando a "McDonaldização" da sociedade defendida por Ritzer (1983).

Oposto à identificação coletiva estaria a liberdade individual. Bauman (2007) é um dos seus defensores, sugerindo uma tomada de decisão altamente 
individualizada pautada na ansiedade de consumir e constituir uma identidade própria por meio do consumo. Ao fazer uma análise social sobre produção e consumo (extrapolando as análises agroalimentares), não só coloca correspondência entre essas duas esferas, mas defende que a sociedade de produtores “a la” Ritzer foi transformada na sociedade de consumidores. Nesse sentido, o fetiche da subjetividade, ou seja, o desejo permanentemente insatisfeito de consumir veio ocupar o espaço do fetiche da mercadoria.

Por outro lado, muitos teóricos defendem que têm ocorrido transformações radicais nos últimos anos, enfatizando a erosão de regras sociais e normativas na definição do que se consome, ocorrendo um desencaixe. Seus principais defensores seriam Beck (1995) e Giddens (I99I), que defendem que estaríamos vivendo em uma sociedade industrial geradora de riscos, que, somada ao excesso de escolhas, informações desencontradas e de responsabilização individual se expressariam em ansiedade e incerteza.

As duas últimas abordagens parecem demonstrar mais elementos explicativos para as tendências atuais que delimitam as formas diferenciadas de consumo que têm promovido mudanças na produção. Estudos realizados no Brasil, que buscaram avaliar quais eram os motivos para a compra de alimentos diferenciados como os orgânicos, verificaram que muito mais que a preocupação com o meio ambiente, os consumidores estavam preocupados com a saúde, com a dieta e com padrões estéticos (Guivant, 2003; Da Silva, 2006).

No apanhado de estudos realizados a partir do consumidor e de seu papel desestabilizador do modelo dominante, Goodman (2002) refere alguns exemplos como a valorização das cozinhas típicas regionais e sua relação com a produção artesanal, com a ecologia e economia local, que podem ser considerados como resposta à globalização, à mudança tecnológica e à rápida concentração industrial. Estudo realizado por Echegaray (20I2) sobre o consumo na América Latina, evidenciou que em média, uma proporção entre um quarto e um quinto dos públicos adultos das três principais economias latinas (Brasil, Argentina e México) já incorporam formas de consumo político indicando a cidadanização das compras e das relações com marcas e produtos.

No bojo desta politização do consumidor, está cada vez mais evidenciado o papel do consumo sustentável como contraponto aos efeitos ambientais e sociais da globalização. Alguns autores vêm propondo diferentes formas de engajamento dos consumidores/cidadãos com respeito às mudanças ambientais em uma sociedade reflexiva, que seriam definidos, a grosso modo, a partir dos três tipos de poder social - o econômico, o ideológico e o político (Spaargaren e Oosterveer, 2010). 
Em relação ao poder econômico ou do mercado que os consumidores teriam, faz-se referência às compras politicamente motivadas, que envolvem boicotes a determinadas empresas, favorecimento de outras e discursos positivos ou negativos sobre marcas em função de suas práticas socioambientais e de mercado. O indivíduo que segue alguns desses caminhos, criticando ou elogiando empresas, premiando (através da compra) ou rechaçando comprar produtos de uma empresa com base em considerações sobre o bem público (justiça social, saúde ambiental, seguridade jurídica, ordem econômica) estaria manifestando um consumo político que teria como foco sua relação com o mercado (Portilho, 2005; Barbosa e Campbell, 2006).

As questões ideológicas ou morais estão ligadas aos estilos de vida (conjunto de hábitos e história de vida) que as pessoas têm, e que são rotinizadas e “des"rotinizadas. A desrotinização pode ocorrer em momentos da vida em que os indivíduos são levados a refletir sobre seus comportamentos e discursos, revendo-os (Callon, Méadel e Rabeharisoa, 2002). Sassatelli (2004) defende a tese de que o consumo é um importante aspecto a considerar-se na transformação de práticas e políticas, em que as pessoas começam a perceber que, modificando-o, é uma forma de começar a buscar um mundo diferente. Em seu estudo sobre discursos, contestação e consumo alimentares alternativos, a autora verifica que nem sempre sanidade, saúde, gosto são preocupações primárias, porém as obrigações morais aparecem com mais poder político na mudança das escolhas alimentares. Nesse sentido, crises alimentares e ambientais e os efeitos da industrialização e massificação do consumo podem incitar os consumidores a tomar outras atitudes levados por questões éticas que se tornam panos de fundo para movimentos como os relacionados ao bem estar animal, ao fair trade, à defesa do local, entre outros.

O engajamento dos consumidores com o Estado no cumprimento dos deveres e obrigações de ambos para o desenvolvimento sustentável caracterizaria o poder do consumo voltado ao seu caráter político. Diz respeito à participação do cidadão nas esferas de decisão política e de seu comprometimento quanto às causas ambientais. Dessa forma, os consumidores cidadãos demandariam segurança ambiental, qualidade de vida para as atuais e futuras gerações, transparência e abertura de informações e participação na formulação e implantação de políticas. Nesta leitura, o consumo sustentável passa a ter seu braço político, além de sua ação junto aos mercados e de sua conformação ética/ideológica.

A reunião desses movimentos e formas de engajamento seria o reflexo de uma pressão material sofrida por diferentes grupos de atores que, em face da incerteza e da adversidade, tentam alguma coisa diferente para sobreviverem ou para "melhor 
viverem", o que coloca o desafio sobre como desenvolver políticas e regulações que possam assistir seu desenvolvimento (Lang, Barling e Caraher, 2009).

Marsden (2003) aponta que em termos regulatórios verifica-se que a evolução para um novo sistema alternativo alimentar não opera uma contradição binária entre o convencional e o alternativo, ou que estamos entrando num terceiro regime agroalimentar, mas um sistema convencional de políticas lutando contra si próprio, como tentativa de acomodar mais demandas externas e políticas. O Estado brasileiro é um exemplo que reflete esta condição ao organizar as políticas relacionadas à produção em dois Ministérios. Soma-se a isso, a necessidade de envolver em suas políticas e regulações a questão ambiental, dificultando ainda mais sua atuação. Nesse sentido, faz-se referência às políticas de Segurança Alimentar e Nutricional (SAN), que apontam para a intersetorialidade e para a conjunção e enfrentamento de múltiplos fatores objetivando sanar as conseqüências do que empiricamente temos chamado de desconexão entre produção e consumo.

Por meio desses três conjuntos de ações dos atores que se constituem por produtores, Estado e principalmente, consumidores, é que o sistema e a cadeia alimentar é permanentemente reavaliada em um processo dinâmico de mudanças que implica necessariamente nos modelos de desenvolvimento perseguidos.

\section{Conclusões}

Diante da complexificação dos movimentos que compõem e determinam diferenciados ou heterogêneos modelos agroalimentares, neste artigo sustentamos a necessidade de ultrapassar as análises dicotômicas da produção e do consumo e avaliar o seu processo dinâmico e constitutivo a partir de teorias mais abrangentes. As formas não dominantes de abastecimento alimentar, como as cadeias curtas de abastecimento sinalizam no sentido de que a sua conformação tem se baseado em ações convergentes entre produtores e consumidores. Estes atores, motivados por diferentes razões corrompem as relações estruturadas, a partir de outras institucionalidades. Nestes termos, a sociologia da alimentação surge como potencial instrumento de aproximação analítica.

No cerne destas discussões, enfatizamos a centralidade da questão alimentar para o desenvolvimento. A alimentação, que era considerada apenas um ato corriqueiro da esfera privada para satisfazer necessidades biológicas, passa a ser um problema social que atinge a saúde, mas também define padrões socioeconômicos e 
ambientais. “O poder está no garfo” já é refrão de movimentos dos consumidores e que explicita o quanto a sua decisão sobre o que adquire e consome, determina a saúde e a doença, mas também o que deve ser produzido, de que forma, por quem, e os reflexos disso no meio em que vive. Ou seja, um simples ato, pode ter muitas conseqüências que afetam não só a vida privada, mas tem interferência global.

Os estudos que se debruçam em entender o que motiva os movimentos que escapam às convencionais estruturas agroalimentares pautadas na durabilidade e na distância, não podem deixar de considerar a importância cada vez maior do consumidor em moldar o sistema agroalimentar. Este artigo considera que, ao mesmo tempo em que ocorre um consumo que caracteriza uma sociedade de massa, também se observam iniciativas de atores, grupos e coletivos que resistem a essa tendência e não se submetem a ela. Este é o caso dos consumidores que buscam um alimento de qualidade, com origem identificada, com personalidade, com cultura, com território. E que, por outro lado, o desenvolvimento agrícola, o agronegócio e a industrialização alimentar contribuem e aprofundam esse consumismo. Para que novas formas de produzir alimentos no meio rural passem a existir, é necessário que, paralelamente e ao mesmo tempo, desenvolva-se uma sociedade que seja capaz de consumir de forma diferente. Essas relações são atávicas aos processos de desenvolvimento social e humano e, assim sendo, propositivas ao estudo do desenvolvimento rural.

No Brasil, verifica-se uma tendência crescente de movimentos, embora muitas vezes dispersos e fragmentados, da sociedade civil e também das políticas públicas e do Estado. Pontua-se o incentivo à formação de cadeias curtas de abastecimento a partir das feiras de pequenos agricultores, dos movimentos agroecológicos e das aquisições públicas de alimentos como o Programa de Aquisição de Alimentos (PAA) e o Programa de Alimentação Escolar (PNAE) como exemplos de políticas de SAN.

No entanto, poucos estudos têm sido realizados na tentativa de verificar como estes processos ocorrem e os resultados que atingem. O que propriamente no Brasil tem induzido produtores e consumidores a reaproximarem-se, diminuindo os diversos elos que os separavam? A procura por alimentos com procedência e frescos tem sido fruto de que motivações, riscos ou crises? Como estes motivos moldam a qualificação dos alimentos, e o que isso pode interferir nas transações econômicas? Qual o papel da sociedade civil, do Estado e de suas regulamentações nesta construção? Quais os efeitos que produz no meio rural e na produção? São efetivos na diminuição das desigualdades sociais, na redistribuição espacial, na renda dos 
agricultores e em sua reprodução? Quais os efeitos que produz no consumo? Podem ser considerados formas de melhorar a saúde das populações? Quais os efeitos que produz ao ambiente -são sustentáveis?

O envolvimento acadêmico na compreensão destas questões é premente visto que os problemas sociais são melhor gerenciados, quando melhor compreendidos. Assim, podem subsidiar o direcionamento das políticas alimentares que se relacionam à agricultura, à saúde e ao meio ambiente. Mas, mais importante que isso é o auto-questionamento dos diversos campos científicos. Quais as propostas científicas e acadêmicas são predominantes e o que deve ser modificado? Que tipo de profissionais e cientistas estamos formando e como estão influenciando os processos de desenvolvimento e de que tipo de desenvolvimento? Para tanto, faz-se necessário diminuir a distância entre as disciplinas e teorias, reclamando enfoques mais amplos e adequados para a formulação, implementação e concretização de práticas e políticas agroalimentares e nutricionais que sejam social e ambientalmente sustentáveis.

\section{Referências}

Amin, A. e Cohendet, P. (2004). Architectures of Knowledge: Firms, Capabilities, and Communities. New York: Oxford.

Barbosa, L. e Campbell, C. (2006) Cultura, consumo e identidade. Rio de Janeiro: Editora FGV.

Bauman, Z. (2007). Vida para consumo: a transformação das pessoas em mercadoria. Rio de Janeiro: Zahar.

Beck, U. (1995). A reinvenção da política: rumo a uma teoria da modernização reflexiva. Em A. Giddens, U. Beck e S. Lash (Orgs.), Modernização reflexiva: política, tradição e estética na ordem social moderna (pp. II-7I). São Paulo: Unesp.

Bonanno, A. (1994). The Locus of Polity Action in a Global Setting. Em A. Bonanno et al. (Org.), From Columbus to ConAgra: the Globalization of Agriculture and Food (25I264). Kansas: University Press.

Bourdieu, P. (2007). A distinção: crítica social do julgamento. Porto Alegre: Zouk.

Callon, M., Méadel, C. e Rabeharisoa, V. (2002). The Economy of Qualities. Economy and Society, $3{ }^{2}(2)$, 194-217.

Clapp, J. e Fuchs, D. (2009). Corporate Power in Global Agrifood Governance. Cambrige: The Mit Press. 
Da Silva, P. (2006). Escolhas e influências dos consumidores de alimentos na modernidade reflexiva: um estudo em supermercados. Dissertação (Mestrado em Sociologia), Setor de Ciências Humanas, Letras e Arte, Universidade Federal do Paraná, Curitiba.

Díaz Méndez, C. e Gómez Benito, C. (2004). Sociología y alimentación. Revista Internacional de Sociología, 6(40), 2I-46.

Douglas, M. e Isherwood, B. (2004). O mundo dos bens: para uma antropologia do consumo. Rio de Janeiro: Edufrj.

Echegaray, F. (2012). Votando na prateleira: a politização do consumo na América Latina. Opinião Pública, I8(I), 44-67.

Fischler, C. (1995). El (b)omnivoro: el gusto, la cocina y el cuerpo. Barcelona: Anagrama.

Friedmann, H. (1993a). After Midas's Feast: Alternative Food Regimes for the Future. Em P. Allen, Food for the Future: Conditions and Contradictions of Sustainability (pp. 213-233). California: John Wiley e Sons, Inc.

Friedmann, H. (1993b). The Political Economy of Food: a Global Crises. New Left Review, 197, 29-57.

Friedmann, H. (2005). From Colonialism to Green Capitalism: Social Movements and Emergence of Food Regimes. Em F. Buttel e P. McMichael (Orgs.), New Directions in the Sociology of Global Development. (pp. 227-264) New York: Elsevier.

Friedmann, H. e McMichael, P. (1989). Agriculture and State System. Sociologia Ruralis, 29(2), 93-II7.

Giddens, A. (1991). As consequências da modernidade. São Paulo: Editora Unesp. Goodman, D. (2002). Rethinking Food Production-Comsumption: Integrative Perspectives. Sociologia Ruralis, 42(4), 272-277.

Goodman, D. (2003). The Quality “Turn” and Alternative Food Practices: Reflections and Agenda. Journal of Rural Studies, I9(I),I-7.

Goodman, D. (2004). Rural Europe redux? Reflections on Alternative Agro-Food Networks and Paradigm Change. Sociologia Ruralis, 44(I),3-16.

Goodman, D. e DuPuis, E. (2002). Knowing Food and Growing Food: Beyond the Production-Consumption Debate in the Sociology of Agriculture. Sociologia Ruralis, 42(I), 5-22.

Goodman, D., Sorj, B. e Wilkinson, J. (1990). Da lavoura às biotecnologias. Rio de Janeiro: Campus.

Guivant, J. (2003). Os supermercados na oferta de alimentos orgânicos: apelando ao estilo de vida ego-trip. Ambiente e Sociedade, 6(2), 63-8I. 
Ilbery, B., Morris, C., Buller, H., Maye, M. e Kneafsey, M. (2005). Product, Process and Place an Examination of Food Marketing and Labelling Schemes in Europe and North America. European Urban and Regional Studies, I2,II6-I32.

Lang, T., Barling, D. e Caraher, M. (2009). Food Policy: Integrating Health, Environment and Society. Oxford: University Press.

Lang, T. e Heasman, M. (2004). Food Wars: The Battle for Minds, Moutbs and Markets. London: Earthscan.

Marsden, T. (2003). The Condition of Rural Sustainability. Assen: Van Gorcun.

Marsden, T.; Banks, J.; Bristow, G. (2000). Food Supply Chain Approaches: Exploring their Role in Rural Development. Sociologia Ruralis, 4o(4), 424-438. McMichael, P. (2009) A Food Regime Genealogy. Journal of Peasant Studies, 36(I), 139-I69.

Mennell, S., Murcott, A. e Oterloo, A. (1992).The Sociology of Food: Eating, Diet and Culture. London: Sage.

Morgan, K., Marsden, T. e Murdoch, J. (2006). Worlds of Food: Place, Power and Provenance in the Food Chain. Oxford: University Press.

Perez-Cassarino, J. (20I2). A construção de mecanismos alternativos de mercados no âmbito da Rede Ecovida de Agroecologia. Tese não publicada (Doutorado em Meio Ambiente e Desenvolvimento), Universidade Federal do Paraná, Curitiba. Ploeg, J. (2008). Camponeses e Impérios Alimentares. Porto Alegre: Ufrgs.

Ploeg, J., Renting, H., Brunori, G., Knickel, K., Mannion, J., Marsden, T., Roest, K., Sevilla-Guzmán, E. e Ventura, F. (2000). Rural Development: from Practices and Policies towards Theory. Sociologia Ruralis, 40(4), 392-408.

Portilho, F. (2005) Sociedade de consumo. Em Sustentabilidade ambiental, consumo e cidadania (pp. 67-76). São Paulo: Cortez.

Ritzer, G. (I983).The McDonaldization of Society. Journal of American Culture, 6(I), I00-I07.

Sassatelli, R. (2004). The Political Morality of Food: Discourses, Contestation and Alternative Consumption. Em M. Harvey, et al. (Org.) Qualities of Food (pp. 176-207). Manchester: University Press.

Schneider, S. (2010) Situando o desenvolvimento rural no Brasil: o contexto e as questões em debate. Revista de Economia Politica, 30(II9), 5II-53I.

Slee, R. e Kirwan, J. (2009). Exploring hybridity in food supply chains. Em Canavari, M., Cantore, N., Castellini, A., Pignatti, E., e Spadoni, R. (Eds.), International Marketing and Trade of Quality Food Products, Wageningen Academic Publishers, Wageningen, Netherlands, pp. I3I-I50. 
Spaargaren, G. e Oosterveer, P. (2010). Citizen-Consumers as Agents of Change in Globalizing Modernity: the Case of Sustainable Consumption. Sustainability, 2(I), I887-1908.

Ward, P., Coveney, J. e Henderson, J. (2010). Editorial: a Sociology of Food and Eating: Why now? Journal of Sociology, 46(4), 347-35I.

Warde, A. (1997). Consumption, Food and Taste. London: Sage.

Wiskerke, J. e Ploeg, J. (2004). Seeds of Transition: Essays on Novelty Production, Niches and Regimes in Agriculture. Assen: Van Gorcum. 